\title{
PENGEMBANGAN CSG (CHILDREN SMART GAMES) UNTUK MENINGKATKAN KEMAMPUAN SISWA SD KELAS V MI AN NAJAHIYYAH
}

\author{
Ika Yuniwati $^{\# 1}$, Ely Trianasari ${ }^{\# 2}$, I Wayan Suardinata ${ }^{* 3}$ Eka Afrida Ermawati $^{* 4}$

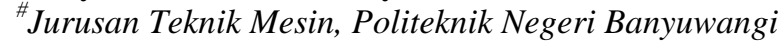 \\ Jl. Raya Jember Km.13 Kabat Banyuwangi \\ ${ }^{1}$ ika@poliwangi.ac.id \\ ${ }^{2}$ ely.trianasariepoliwangi.ac.id \\ *Jurusan Teknik Informatika, Politeknik Negeri Banyuwangi \\ Jl. Raya Jember Km13 Kabat Banyuwangi \\ ${ }^{3}$ wayan.suardinata@poliwangi.ac.id \\ ${ }^{4}$ ekaafrida22@poliwangi.ac.id
}

\begin{abstract}
Abstrak
Bahasa Inggris merupakan bahasa internasional yang diajarkan di segala usia mulai PAUD sampai dengan Perguruan Tinggi. Kemampuan Bahasa Inggris peserta didik sangat bermanfaat untuk bekal di masa mendatang agar mampu berkomunikasi dengan baik, khususnya untuk menghadapi era disrupsi. Dimana di era ini terjadi pertukaran informasi tanpa batas. Hasil pembelajaran bahasa inggris di Indonesia masih cukup rendah, khususnya ditempat mitra yaitu MI An-Najahiyyah kelas 5. Oleh karena itu dibutuhkan suatu inovasi pembelajaran yang mampu membuat peserta didik tertarik mempelajari bahasa inggris. Berdasarkan permasalahan yang dihadapi mitra, pengusul mengembangkan game sebagai media pembelajaran bahasa inggris yang berbasis Android. Game yang dikembangkan menekankan pada materi bahasa inggris kelas 5 SD/MI sederajat. Didalam game ini terdapat 3 level yang berbeda tingkat kesulitannya, level 1 berisi permainan kata yang dikemas dengan model quiz, level 2 berisi permainan kalimat dengan model puzzle dan level 3 menekankan pada teks cerita yang dikemas dalam model role-playing game. Pengusul juga memberi panduan di menu utama untuk mempermudah siswa mempelajari cara bermain di setiap level. Setelah dilakukan pengembangan game kemudian dilakukan validasi oleh guru bahasa inggris mengenai kesesuaian game dengan kemampuan siswa kelas 5. Setelah game tervalidasi kemudian dilakukan sosialisasi ke guru-guru MI An-Najahiyyah mengenai game yang dikembangkan. Setelah itu dilakukan pendampingan pembelajaran bahasa inggris sebanyak dua kali yaitu Pembelajaran Game Level 1 di MI An Najahiyyah dan Pembelajaran Game Level 2 dan 3 di Politeknik Negeri Banyuwangi. Kegiatan yang pertama yaitu pengembangan Game Level 1 dan pendampingan pembelajaran di MI An Najahiyyah. Tahap berikutnya memfinalisasi Game Level 2 dan Game Level 3 kemudian melakukan pembelajaran di Politeknik Negeri Banyuwangi.
\end{abstract}

Kata Kunci - Children Smart Games (CSG), Kemampuan Bahasa Inggris, Siswa Kelas V, MI An Najahiyyah

\section{PENDAHULUAN.}

Bahasa Inggris mulai diajarkan di Indonesia sejak anak bersekolah di PAUD hingga Perguruan Tinggi. Berbagai macam penerapan metode dan kurikulum yang diajarkan untuk mengembangkan kemampuan siswa dalam memahami bahasa inggris. Meskipun hal tersebut sudah dilakukan namun hasil yang didapatkan masih belum bisa maksimal dalam meningkatkan pemahaman siswa mengenai bahasa inggris. Contoh usaha yang dilakukan pemerintah guna meningkatkan pemahaman bahasa inggris masyarakat Indonesia yaitu dengan memperkenalkan bahasa inggris di ranah sekolah dasar (Nugroho, 2013).

Ketika bahasa inggris memasuki ranah sekolah dasar mulai muncul permasalahan seperti sulitnya siswa dalam memahami makna dari sebuah kata, menirukan cara pengucapan kata dan penulisan kata. Timbulnya masalah ini menjadi hal yang harus diwaspadai karena jika masalah ini tidak bisa dipecahkan maka generasi penerus bangsa akan sulit menghadapi era disrupsi. Dimana di era disrupsi tuntutan terhadap pendidikan semakin tinggi karena terjadi perubahan yang mendasar diberbagai industri. Di era ini terjadi pertukaran informasi yang tidak terbatas. Sehingga kemampuan anak didik dalam bidang bahasa khususnya bahasa inggris harus mulai ditingkatkan (Oey, dkk., 2017). Oleh karena itu diperlukan inovasi yang bisa membangun semangat anak untuk bisa mempelajari bahasa inggris sebagai bahasa internasional.

Sudah sewajarnya metode pembelajaran bahasa inggris harus dikembangkan guna mempermudah generasi penerus bangsa untuk memahami bahasa inggris. Media permainan bisa dijadikan inovasi untuk meningkatkan semangat minat belajar mereka (Riski, 2017). Terutama siswa sekolah dasar yang masih memiliki tingkat konsentrasi tinggi. Akan tetapi gameplay yang harus diterapkan adalah gameplay yang mengacu pada pembelajaran bahasa inggris seperti halnya speaking, reading, dan writing.

Mitra dalam pengabdian ini yaitu MI ANNAJAHIYYAH Pakistaji masih menggunakan proses pembelajaran bahasa inggris. Sehingga daya 
serap ilmu siswa dalam memahami bahasa inggris masih kurang baik. Oleh karena dibutuhkan suatu inovasi pembelajaran. Salah satunya menggunakan game berbasis android. Pembelajaran menggunakan multimedia atau game berguna untuk mendukung kegiatan belajar mengajar. Menurut Goretti, dkk (2014) manfaat penggunaan multimedia dalam kegiatan belajar mengajar adalah dapat memperjelas penyajian informasi yang diberikan oleh guru kepada siswa, mampu meningkatkan inovasi, interaksi langsung antar siswa dengan guru guna memperlancar proses pembelajaran, dapat mengatasi keterbatasan indra, ruang dan waktu, serta mampu memberikan kesamaan pengalaman kepada siswa tentang peristiwa sekitar.

Kondisi ekonomi siswa kelas 5 MI ANNajahiyyah Pakistaji tergolong masyarakat menengah ke atas dibidang ekonomi. Hampir seluruh siswa kelas 5 MI AN-NAJAHIYYAH Pakistaji memiliki HP Android. Jadi dapat disimpulkan siswa kelas 5 MI AN-NAJAHIYYAH Pakistaji merupakan masyarakat dengan tingkat ekonomi menengah keatas. Hal tersebut memberikan dampak bahwa pembelajaran bahasa inggris berbasis android yang akan dilakukan tidak akan memberikan kesulitan kepada siswa dalam segi adanya sarana pembelajaran. Untuk siswa yang tidak memiliki HP Android dapat melakukan pembelajaran di sekolah setelah pengabdian ini selesai.

\section{TARGET DAN LUARAN}

Untuk mengatasi kendala dalam pembelajaran yang dialami siswa kelas 5 MI AN-NAJAHIYYAH maka dilakukan pengembangan game berbasis android, dimana game ini dibuat setelah melakukan diskusi materi oleh mitra. Setelah dilakukan pengembangan nantinya akan divalidasi oleh guru kelas 5 agar game yang dikembangkan sesuai dengan kondisi pengetahuan siswa kelas 5 SD di MI ANNAJAHIYYAH.

Game yang dikembangkan menekankan pada materi bahasa inggris kelas $5 \mathrm{SD} / \mathrm{MI}$ sederajat. Didalam game ini terdapat 3 level yang berbeda tingkat kesulitannya, level 1 berisi permainan kata yang dikemas dengan model quiz, level 2 berisi permainan kalimat dengan model puzzle dan level 3 menekankan pada teks cerita yang dikemas dalam model role-playing game. Pengusul juga memberi panduan di menu utama untuk mempermudah siswa mempelajari cara bermain di setiap level.

\section{METODE PELAKSANAAN}

Adapun proses pengembangan game ini melalui beberapa tahapan yaitu pembuatan modul game dan game yang digunakan dalam pembelajaran. Tahap selanjutnya sosialisasi dan pendampingan pembelajaran bahasa inggris menggunakan game yang telah dikembangkan.
Tahap Pembuatan Modul dan Game. Pembuatan modul digunakan sebagai media penunjang dalam pelaksanakan program inovasi game berbasis android di MI AN-NAJAHIYYAH Pakistaji. Modul yang dibuat berisikan tentang tata cara gameplay atau cara bermain yang ada didalam permainan game. Metode juga berisi tips-tips untuk bisa mempelajari bahasa inggris dengan menyenangkan. Kemudian dilakukan validasi oleh guru bahasa inggris.

Kemudian dilanjutkan Tahap Sosialisasi. Tahap Sosialisasi dilakukan agar siswa dapat mengerti tentang game yang akan diterapkan sehingga menambah pengetahuan siswa tentang cara menyelesaikan game yang dikembangkan. Kegiatan ini dilakukan di ruang kelas 5 MI ANNAJAHIYYAH Pakistaji dan mengundang para guru, karyawan serta siswa kelas 5 MI ANNAJAHIYYAH Pakistaji.

Tahapan berikutnya yaitu Tahap Pendampingan Game yang dikembangkan merupakan game edukasi berbasis Android yang dirancang untuk meningkatkan pemahaman siswa sekolah dasar terhadap materi bahasa inggris. Game yang dikembangkan dinamakan Children Smart Games pelaku utama sebagai pemain game ini adalah siswa kelas 5 MI AN-NAJAHIYYAH Pakistaji. Siswa akan dibimbing agar dapat memainkan game dari level pertama hingga akhir. Adapun metode pelaksanaan permainan pada game di MI ANNAJAHIYYAH Pakistaji yaitu Pendampingan Game tahap awal Pendampingan game tahap awal meliputi pengenalan, tata cara, tips dan trik, hingga memainkan Children Smart Games level 1. Pada tahap awal atau level 1 yang bertipe game quiz siswa diarahkan untuk memahami bahasa inggris dengan metode visualisasi. Berisi kata bahasa inggris yang hurufnya diacak kemudian dicocokan dengan gambar benda-benda. Apabila jawaban benar maka siswa dapat memperoleh nilai dan dapat lanjut di tahap berikutnya.

Pendampingan Game tahap menengah. Pendampingan game tahap menengah siswa diarahkan untuk bisa memahami dan menuntaskan game di level 2 yang bertipe puzzle. Pemain harus menyusun kata-kata yang diacak untuk membentuk sebuah kalimat yang sesuai dengan gambar yang disajikan. Bila gambar tersebut dibuka semakin banyak maka semakin kecil nilai yang didapatkan. Pada Game Level 2 diharapkan bisa meningkatkan pemahaman siswa terhadap kalimat bahasa inggris.

Pendampingan Game tahap akhir yaitu Pendampingan game tahap akhir siswa diarahkan untuk bisa memahami dan menuntaskan level akhir game yaitu level 3. Pada level terakhir yang bertipe role-playing game (RPG) karakter utama game adalah seorang pendekar yang ingin menyelamatkan dunia. Pada awalnya tokoh utama berada di sebuah pedesaan yang tentram hingga suatu hari ada sebuah 
monster yang menculik keluarganya. Karakter utama akan melakukan perjalanan yang jauh untuk bisa mencapai orang tuanya dengan melalui banyak rintangan dan musuh yang menghalangi. Level 3 diharapkan bisa meningkatkkan pemahaman siswa terhadap kata, kalimat dan dialog percakapan bahasa inggris.

\section{IV.HASIL DAN PEMBAHASAN}

Pembuatan CSG terdiri dari 3 level antara lain level 1 yang bertipe game quiz siswa diarahkan untuk memahami bahasa inggris dengan metode visualisasi. Benda-benda yang digunakan dalam game antara lain bagian dari tubuh, transportasi, buah-buahan, dan sayur mayur Game Level 1 dapat dilihat pada Gambar 1.

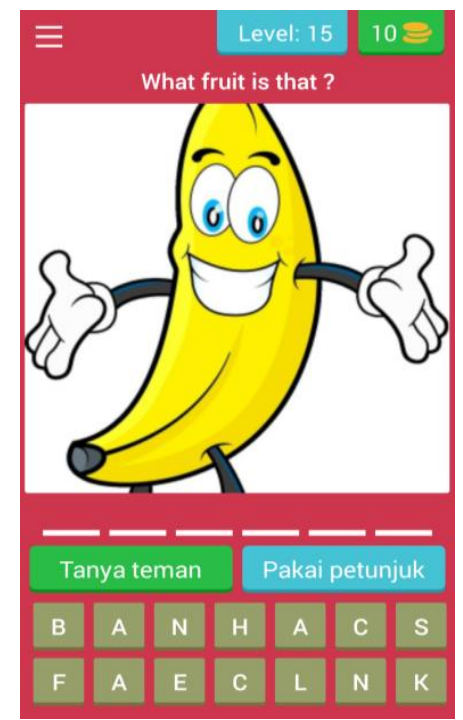

Gambar 1.Contoh Game Level 1 CSG

Pada Game Level 2 siswa diarahkan untuk bisa memahami dan menuntaskan game di level 2 yang bertipe puzzle. Game Level 2 dapat dilihat pada Gambar 2.

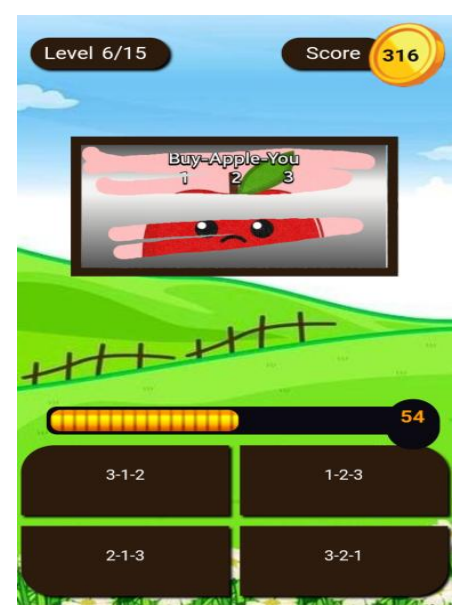

Gambar 2.Contoh Game Level 2 CSG
Kemudian Pada level terakhir yang bertipe roleplaying game $(R P G)$ karakter utama game adalah seorang pendekar yang ingin menyelamatkan dunia. Game Level 3 dapat dilihat pada Gambar 3.

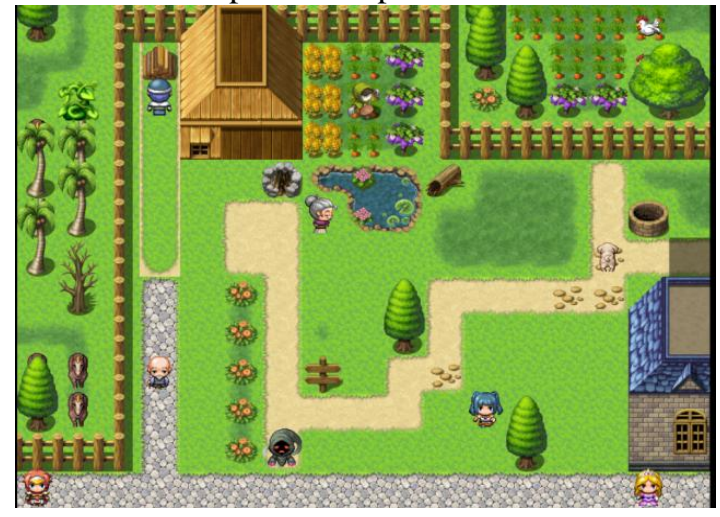

Gambar 3.Contoh Game Level 3 CSG tampilan awal

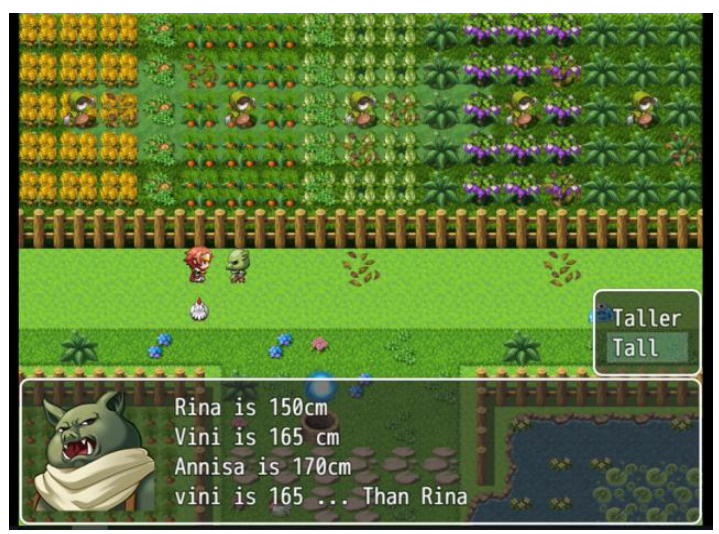

Gambar 4 Rintangan yang dihadapi ketika memasuki kastil adalah menjawab pertanyaan

Proses pembelajaran pada bulan Oktober 2018 dengan 2 kali proses pembelajaran yaitu proses pembelajaran level 1 di MI An Najahiyyah pada tanggal 6 Oktober 2018 dan proses pembelajaran level 2 dan 3 di Politeknik Negeri Banyuwangi pada tanggal 26 Oktober 2018. Pembelajaran di MI An Najahiyyah terdiri dari beberapa bagian yang pertama proses instal game ke Android siswa seperti pada Gambar 5.

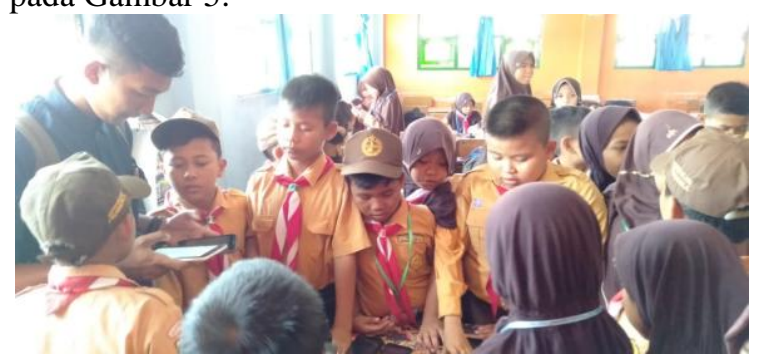

Gambar 5. Proses Instalasi Game Sebelum Pendampingan

Setelah dilakukan proses instal game kemudian dilakukan pembelajaran oleh dua orang dosen Bahasa Inggris Politeknik Negeri Banyuwangi. 
Siswa dibagi menjadi dua kelas dengan proses pembelajaran pendahuluan seperti pada Gambar 6 .

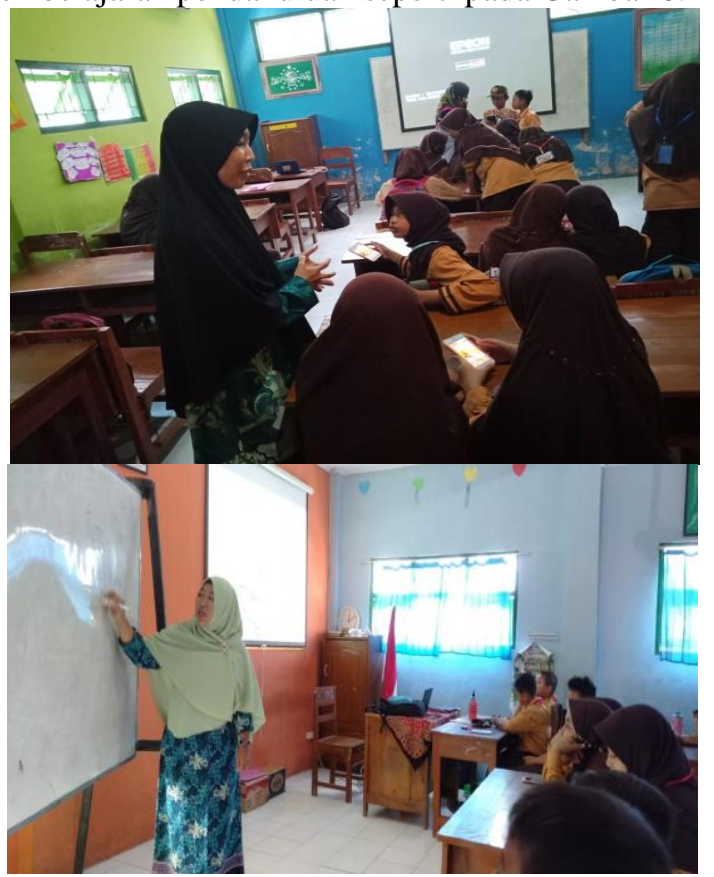

Gambar 6. Proses Pendampingan Oleh Dosen Bahasa Inggris

Proses pembelajaran kemudian dilanjutkan melalui pembelajaran mandiri siswa melalui game yang terinstal pada android masing-masing siswa dengan didampingi mahasiswa Politeknik Negeri Banyuwangi Program Studi Teknologi Informatika dan Manajemen Bisnis Pariwisata. Untuk siswa yang tidak memiliki android menggunakan Tablet yang disediakan oleh Tim PKM. Gambar Proses pembelajaran mandiri seperti pada Gambar 7.

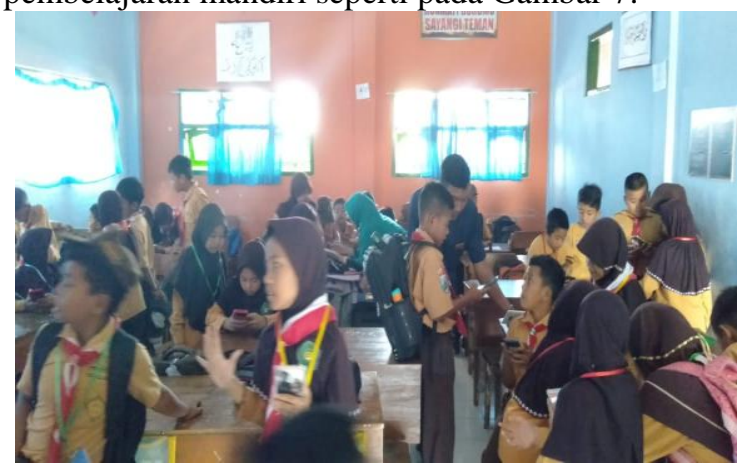

Gambar 7. Proses Pendampingan Oleh Dosen Bahasa Inggris

Seluruh siswa mengisi kuesioner setelah dilakukan pembelajaran, untuk mendapatkan umpan balik dari game yang dibuat. Hasil dari kuesioner siswa merasa gamenya sangat menyenangkan dengan gambar yang cukup bagus. Setelah dilakukan proses pembelajaran level 1 pada kegiatan PKM ini dilakukan serah terima Tablet Android kepada
Kepala Sekolah MI An-Najahiyyah, nampak pada Gambar 8.

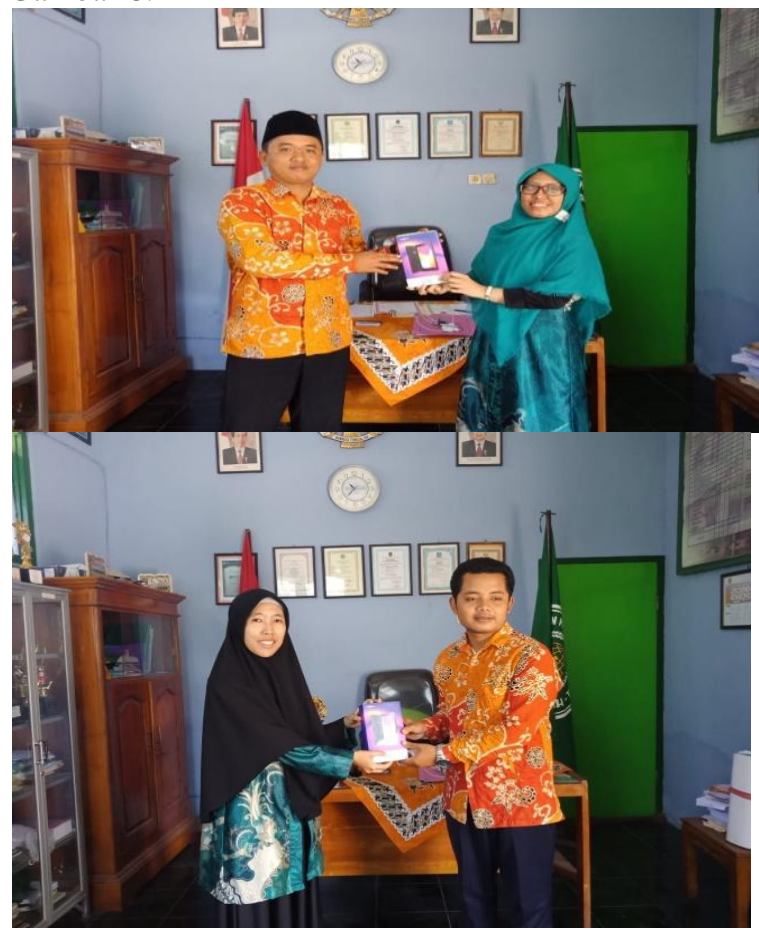

Gambar 8. Serah Terima Tablet yang Terinstal Game

Tahapan berikutnya yaitu pembuatan game level 2 dan level 3. Level 2 siswa diarahkan untuk bisa memahami dan menuntaskan game di level 2 yang bertipe puzzle. Kemudian Pada level terakhir yang bertipe role-playing game $(R P G)$ karakter utama game adalah seorang pendekar yang ingin menyelamatkan dunia. Setelah melakukan penyelesaian level 2 dan level 3 kemudian melakukan proses pembelajaran. Proses pembelajaran dilakukan di Politeknik Negeri Banyuwangi pada tanggal 26 Oktober 2018 melalui proses yang sama dengan proses pembelajaran di MI An-Najahiyyah. Proses pembelajaran Game Level 2 dapat dilihat pada Gambar 8. Proses Pembelajaran Game Level 3 dapat dilihat pada Gambar 9.

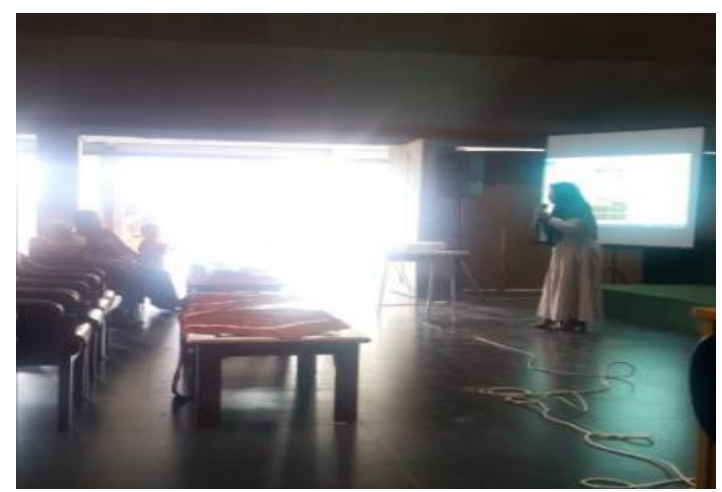

Gambar 9. Pembelajaran Game Level 2 


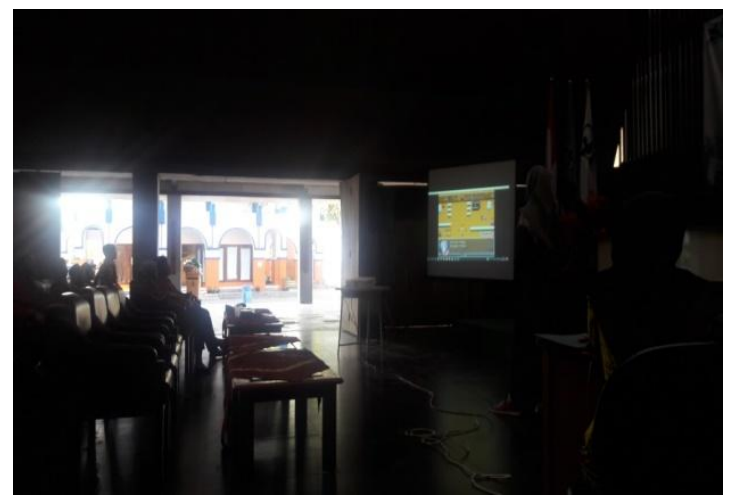

Gambar 10. Pembelajaran Game Level 3

\section{KESIMPULAN}

Kegiatan pengabdian masyarakat yang telah dilaksanakan yaitu proses pembuatan Game Level 1 dan proses pembelajaran game level 1 di MI-An Najahiyyah. Proses pembuatan pembuatan Level 2 dan Level 3 serta pembelajarannya dilakukan di Politeknik Negeri Banyuwangi. Game yang dikembangkan memberikan motivasi kepada siswa kelas atas MI-An Najahiyyah untuk mempelajari Bahasa Inggris.

\section{UCAPAN TERIMA KASIH}

Kami mengucapkan terima kasih kepada Politeknik Negeri Banyuwangi yang telah memberikan dukungan pendanaan pada kegiatan pengabdian ini melalui Pusat Penelitian dan Pengabdian Kepada Masyarakat.

\section{DAFTAR PUSTAKA}

[1] Goretti, M., dkk. 2014. Penerapan Media Audio Visual dalam Pembelajaran Bahasa Inggris (Studi kasus di SMPN 3 Bawen). Jurnal Teknologi Pendidikan dan Pembelajaran. Vol 2. No 1 : 79-92

[2] Nugroho, Sentot. 2013. Pembuatan Media Pembelajaran Pengenalan Dasar Bahasa Inggris Untuk Kelas Satu dan Dua Pada Sekolah Dasar Negeri Kancangan. Disampaikan pada Seminar Riset Unggulan Nasional Informatika dan Komputer FTI UNSA. Vol 2 No 1 : 90-93.

[3] Riski, A., dkk. 2017. Media Pembelajaran Interaktif Bahasa Inggris Kelas V Sekolah Dasar Negeri 02 Cinere. Jurnal CoreIT. Vol 3. No $1: 9-13$.

[4] Oey, dkk. 2017. Era Disrupsi Peluang dan Tantangan Pendidikan Tinggi. Jakarta Barat : Akademi Ilmu Pengetahuan Indonesia. 